\title{
Optimal Framework for reconfiguration of manufacturing setups using Non Dominating Sorting Genetic Algorithms
}

\author{
[ Eram Asghar, Aamer Ahmad Baqai, Ramshah Ahmad, Nazish Liaqat ]
}

\begin{abstract}
The concept of reconfigurable manufacturing system has emerged drastically as it reduces the product lead time and meets with the market demand efficiently. The performance of a manufacturing system lies on a set of planning and scheduling data incorporated with the machining capabilities keeping in view the market demands. The proposed work focuses on the formulation of an optimal framework for production over part families. Machine's kinematic configurations are generated considering tool's degree of freedom. The application of non-dominating sorting genetic algorithms over machine configurations makes this approach more reliable. A case study has been presented to illustrate the application of proposed model based on the technological constraints.
\end{abstract}

Keywords-Reconfigurable manufacturing system (RMS)), Multi objective Genetic Algorithm (MOGA), Non dominating Sorting Genetic Algorithms (NSGA), Couvercle De Vileberequin $(C D V)$, Corps de Pompe a Huile moteur $(C P H C)$.

\section{Introduction}

Manufacturing companies started facing unpredictable market fluctuations in the start of $20^{\text {th }}$ century. Due to the unexpected demands, product design needs to be modified accordingly. The shorter product life cycle are urging the manufacturers to modify their systems to the frequent design changes. Thus there is a need of a reconfigurable model to accommodate all the design changes with customized flexibility and capacity. Reconfigurability is an engineering technology that deals with the design and manufacturing system to make required modifications to respond cost effectively to market changes. The concept of RMS was introduced to sustain in global market by rapid adjustment and modification of production capacity and system functionality in reaction to abrupt market demands. In this research work reconfiguring methodology has been introduced to switch the production from one part to another through the application of non-dominating sorting genetic algorithms.

\section{Eram Asghar}

Ghulam Ishaq Khan Institute of Engineering Sciences and Technology, Pakistan

\section{Aamer Ahmad Baqai}

National University of Sciences and Technology,

Pakistan

Ramshah Ahmad

Ghulam Ishaq Khan Institute of Engineering Sciences and Technology, Pakistan

\section{Nazish Liaqat}

National University of sciences and Technology,
Pakistan

\section{Related Work}

In RMS field, research is being in progress for the development of changeability enablers to adjust and rebalance the system configuration depending upon the requirement. Changeability concept allows the change enablers at different levels of any industry to sustain the life cycle of manufacturing system. Responsiveness is required at different levels in manufacturing system in terms of changeability and scalability. Reduction in product cost and responsiveness can be observed by customizing the machining capabilities at product design stage and then the reuse of these capabilities at reconfiguration stage [1,2]. One of the major contributions in configuration selection was carried out by Youssef and ElMaraghy [3]. It is a novel approach for the selection of machine configurations in two phases. In phase one, near optimal configuration is selected considering different demand scenarios using real coded GA and Tabu Search (TS). The second phase deals with discrete optimization to search the optimal configurations from the ones that were produced in the phase one. Reconfigurable Machine Tool (RMT) is modular type of machine tool having the characteristics like convertibility, integrability and modularity [4]. These characteristics of RMS allow mass customization and rapid response to the product design change. Machine kinematic configurations are generated from the set of functional requirements and process plans in order to design RMTs as stated by Moon and Kota [5]. Another approach was proposed by K.K Goyal [6] for optimal assignment of machine in parallel setups. In this approach optimal configurations are generated through an optimization technique of non-dominating sorting NSGA and adopted TOPOSIS ranking theory. This approach leads to the machine tool reconfiguration by adding or subtracting machine modules going through different performance measures. NSGA-II technique has also been used by Abderrahman et al [7] in the selection of optimal machines from the set of candidate machine configurations. In this research work multi product case with high degree of freedom can be considered as future work. With the idea of co-evolution the machine configurations can be used for different product designs over and over again preserving the feasibility of the system for a long period of time. P.Mohapatra et al [8] proposed the method to bridge the gap between scheduling and setup planning by grouping the machining features on the basis of tool approach directions (TAD), adopted NSGA - II and fuzzy set theory to get the best pareto optimal solution. Recently, Ahmed Azab et al [9] proposed a methodology in modeling of large problems which include sub family sequencing and parts in each sub family to minimize the maximum completion time using mathematical programming software. Reconfigurable Manufacturing Systems are built to effectively respond to 
market changes. Although plenty of work exists on the issues of RMS but a wide scope of study is still required in all fields of RMS. To have real implementation of RMS, a reconfigurable framework is required through which production around a part family can be made possible with minimum machine capabilities.

\section{Proposed Methodology}

The proposed optimized reconfigurable model is required that should be intelligent enough to track and accommodate the design modifications and system requirements. In reconfigurable manufacturing environment, machines exist in different configurations with customized flexibility allowing the rapid change of machine configuration. Each machine consists of various modules providing different tool and orientations of parts. Configuration changeover depends upon the machine's visibility for that particular operation.

\section{A. Optimal Machine Configuration}

Machine's structural configuration is generated on the basis of orientation required to generate any particular feature of the part family. The inputs of this algorithm are alternative process plans and possible tool approach directions. Depending upon the machine's accessibility and tool approach directions, machine's kinematic configurations have been generated for each process plan (see figure 1).

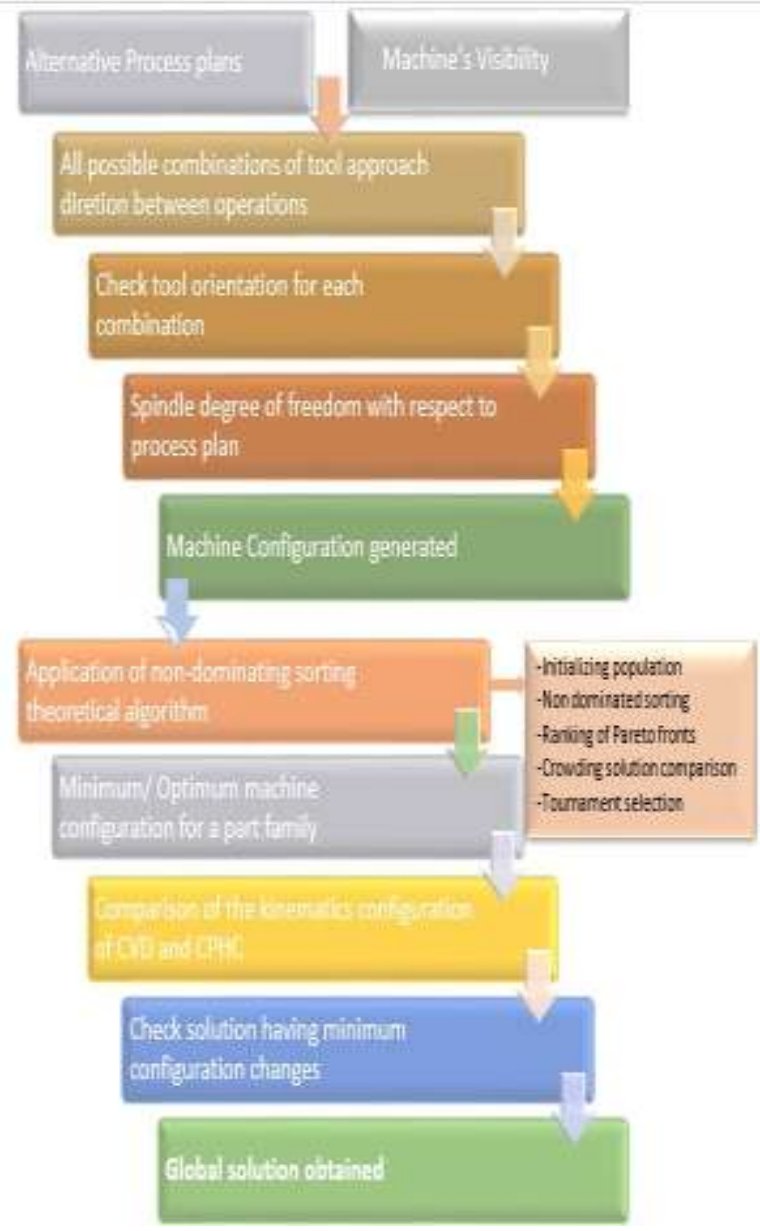

Figure 1. Algorithm for Optimal Machine Configuration
Mostly optimization of engineering designs are carried out through evolutionary algorithms which are stochastic global search methods inspired by natural evolution. These algorithms are basically inspired from different natural phenomena and make use of the best character of that phenomenon. As discussed earlier, this algorithm searches the global optimum solution and because of its extreme robustness the probability of getting the minimum global solution increases. GA's are the powerful global search algorithm was introduced in 1975 by John Henry Holland. It is method of searching the best solution from population to population by using the natural selection. The major difference of GAs from other search techniques is its initialization of random solutions called population and each individual in a population is chromosome representing the solution to the problem [10]. Multi objective Genetic Algorithms (MOGAs) are the extended form of single objective GAs. Non dominating sorting genetic algorithms (NSGA) works by minimizing each objective first and then by computing the overall fitness of the objectives as a single objective function leads towards the single optimum solution. In most of the multi objective problems, a set of solutions exist from the large search region which is superior from other solutions in the search space, these solutions are called pareto optimals or non dominated solutions [11]. If in case, no solution in the feasible region is better than other, then any of the solution is acceptable. Sometime designers are interested to get all alternative solutions for this reason the concept of pareto optimality is used for multi-criteria optimization. The idea behind this algorithm is to rank the solutions according to their non domination count to get a set of pareto optimal solutions. Non dominated solutions are those which are not dominated by any other solution in the feasible design space [12]. The aim of this research work is to minimize the machine capabilities and reconfigure the production system optimally. Therefore considering the criteria of tool change, set up change and part rotation the genetic algorithms have been applied.

\section{Results and Discussion}

The developed model has been evaluated applied on two case study parts CDV and CPHC belonging to same part family. Specifications of these parts are mentioned in annex. The tool axis available depending upon the machine's visibility and its movement for different features of process plans are presented in the schematic diagram of process plan depicted in figure 2 .

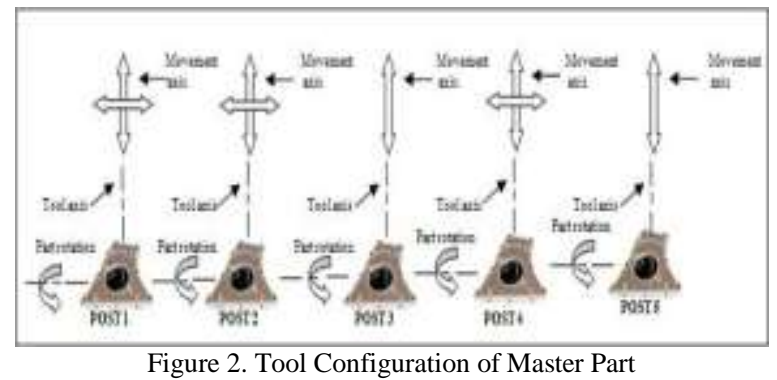

Figure 2. Tool Configuration of Master Part 
TABLE I: Optimal Machine Configuration for CDV

\begin{tabular}{|l|c|c|c|c|c|c|c|c|c|}
\hline \multirow{2}{*}{ Ops } & \multicolumn{3}{|c|}{ Machine Configurations } & \multicolumn{3}{c|}{$\begin{array}{c}\text { Spindie Angle of } \\
\text { Rotation }\end{array}$} \\
\cline { 2 - 10 } & $\mathrm{X}$ & $-\mathrm{X}$ & $\mathrm{Y}$ & $-\mathrm{Y}$ & $\mathbf{Z}$ & $-Z$ & $\alpha$ & $\beta$ & $\Upsilon$ \\
\hline OP3 & 0 & 0 & 1 & 0 & 0 & 0 & -90 & 0 & 0 \\
\hline OP1 & 0 & 0 & 0 & 0 & 0 & 1 & 0 & 0 & 0 \\
\hline OP12 & 0 & 0 & 0 & 0 & 0 & 1 & 0 & 0 & 0 \\
\hline OP7 & 0 & 0 & 0 & 0 & 0 & 1 & 0 & 0 & 0 \\
\hline OP5 & 0 & 0 & 0 & 0 & 1 & 0 & 0 & 150 & 0 \\
\hline OP6 & 0 & 0 & 0 & 0 & 1 & 0 & 0 & 180 & 0 \\
\hline OPs & 0 & 0 & 0 & 0 & 1 & 0 & 0 & 150 & 0 \\
\hline OP4 & 0 & 0 & 0 & 0 & 0 & 1 & 0 & 0 & 0 \\
\hline OP2 & 0 & 0 & 1 & 0 & 0 & 0 & -90 & 0 & 0 \\
\hline OP9 & 0 & 0 & 0 & 0 & 1 & 0 & 0 & 180 & 0 \\
\hline OP10 & 0 & 0 & 0 & 0 & 0 & 1 & 0 & 0 & 0 \\
\hline OP11 & 0 & 0 & 0 & 0 & 0 & 1 & 0 & 0 & 0 \\
\hline OP13 & 0 & 0 & 0 & 0 & 0 & 1 & 0 & 0 & 0 \\
\hline OP14 & 0 & 0 & 0 & 0 & 0 & 1 & 0 & 0 & 0 \\
\hline
\end{tabular}

TABLE II: Process Planning Parameter CDV

\begin{tabular}{|c|c|}
\hline No of setup changes & 4 \\
\hline No of Tool changes & 10 \\
\hline Part rotation & 4 \\
\hline Spindle degree of freedom & 7 \\
\hline
\end{tabular}

The configurations obtained from the master part are compared with all possible combinations of machine configurations. As a result minimum machine configuration is generated for CPHC and the system is adjusted for production accordingly. These configurations and process planning parameters are shown in table 3 and 4.

TABLE III: Optimal Machine Configuration for CPHC

\begin{tabular}{|l|c|c|c|c|c|c|c|c|c|}
\hline \multirow{2}{*}{ Ops } & \multicolumn{9}{|c|}{ Configurations } \\
\cline { 2 - 10 } & $\mathbf{X}$ & $-\mathbf{X}$ & $\mathbf{Y}$ & $-\mathbf{Y}$ & $\mathbf{Z}$ & $-\mathbf{Z}$ & $\boldsymbol{\alpha}$ & $\boldsymbol{3}$ & \multicolumn{3}{c|}{ Rotation } \\
\hline OP1 & 0 & 0 & 1 & 0 & 0 & 0 & -90 & 0 & 0 \\
\hline OP5 & 0 & 0 & 0 & 0 & 0 & 1 & 0 & 0 & 0 \\
\hline OP6 & 0 & 0 & 0 & 0 & 0 & 1 & 0 & 0 & 0 \\
\hline OP13 & 0 & 0 & 0 & 0 & 0 & 1 & 0 & 0 & 0 \\
\hline OP2 & 0 & 0 & 1 & 0 & 0 & 0 & -90 & 0 & 0 \\
\hline OP7 & 0 & 0 & 0 & 0 & 0 & 1 & 0 & 0 & 0 \\
\hline OP14 & 0 & 0 & 0 & 0 & 0 & 1 & 0 & 0 & 0 \\
\hline OP3 & 0 & 0 & 0 & 0 & 0 & 1 & 0 & 0 & 0 \\
\hline OP4 & 0 & 0 & 0 & 0 & 0 & 1 & 0 & 0 & 0 \\
\hline OP20 & 0 & 0 & 0 & 0 & 0 & 1 & 0 & 0 & 0 \\
\hline OP15 & 0 & 0 & 0 & 0 & 0 & 1 & 0 & 0 & 0 \\
\hline OP21 & 0 & 0 & 0 & 0 & 0 & 1 & 0 & 0 & 0 \\
\hline OP8 & 0 & 0 & 0 & 0 & 0 & 1 & 0 & 0 & 0 \\
\hline OP22 & 0 & 0 & 0 & 0 & 0 & 1 & 0 & 0 & 0 \\
\hline OP23 & 0 & 0 & 0 & 0 & 0 & 1 & 0 & 0 & 0 \\
\hline OP9 & 0 & 0 & 0 & 0 & 0 & 1 & 0 & 0 & 0 \\
\hline OP24 & 0 & 0 & 0 & 0 & 0 & 1 & 0 & 0 & 0 \\
\hline OP10 & 0 & 0 & 0 & 0 & 0 & 1 & 0 & 0 & 0 \\
\hline OP11 & 0 & 0 & 0 & 0 & 0 & 1 & 0 & 0 & 0 \\
\hline OP12 & 0 & 0 & 0 & 0 & 0 & 1 & 0 & 0 & 0 \\
\hline OP16 & 0 & 0 & 0 & 0 & 0 & 1 & 0 & 0 & 0 \\
\hline OP17 & 0 & 0 & 0 & 0 & 0 & 1 & 0 & 0 & 0 \\
\hline OP18 & 0 & 0 & 0 & 0 & 0 & 1 & 0 & 0 & 0 \\
\hline OP19 & 0 & 0 & 0 & 0 & 0 & 1 & 0 & 0 & 0 \\
\hline OP25 & 0 & 0 & 0 & 0 & 0 & 1 & 0 & 0 & 0 \\
\hline OP26 & 0 & 0 & 0 & 0 & 0 & 1 & 0 & 0 & 0 \\
\hline OP27 & 0 & 0 & 0 & 0 & 0 & 1 & 0 & 0 & 0 \\
\hline OP28 & 0 & 0 & 0 & 0 & 0 & 1 & 0 & 0 & 0 \\
\hline
\end{tabular}

TABLE IV: Process Planning Parameters of CPHC

\begin{tabular}{|c|c|}
\hline No of setup changes & 8 \\
\hline No of Tool changes & 24 \\
\hline Part rotation & 0 \\
\hline Spindle degree of freedom & 4 \\
\hline
\end{tabular}

The output of the proposed algorithm shows minimum axis of spindle rotation for each operation. The optimum machine configurations for the master part CDV are shown in table 1 along with the spindle rotational angles and process planning parameters are shown in table 2 . It is evident from table 2 that minimum changes have been obtained through the application of MOGA.

The above case study shows that by applying the proposed approaches, an optimized reconfigurable framework can be obtained. This framework includes: optimum process plans, optimum machine's kinematic configurations and reconfiguration changeability extent. RPP represents important changeability enablers for product and manufacturing system evolution. It cost effectively manages the change in product and modify the system accordingly.

\section{Conclusion and Future Work}

This research work is concerned with the development of an integrated approach for modifying the setup according to the variations in product design. Application of NSGA yields the system towards global optimum. The presented algorithm can manufacture the part family with minimum production changeover time and optimal machine capabilities. This work can be extended for multiple and parallel setups. Extension of the same algorithm by increasing the number of parts, this would add the versatility in the system.

\section{References}

[1] H.P.Wiendahl, H.A.ElMaraghy, P.Nyhuism M.F.Zah, N.Duffie, M.Brieke "Changeable Manufacturing-classification, design and operation", Annuals of CIRP, 2007, Vol. 56/2, pp.783-809.

[2] A.Azab, H.A.ElMaragh, "Mathematical Modeling for reconfigurable process planning", Intelligent Manufacturing Systems, Annuals of the CIRP, 2007, Vol. 56/1.

[3] M.Youssef, H.A. ElMaraghy, "Optimal configuration selection for reconfigurable manufacturing systems", International Journal of Manufacturing Systems, 2007, Vol.19, pp. 67-106.

[4] Yorem Koren, Moshe Shpitalni, "Design of reconfigurable manufacturing systems". Journal of Manufacturing Systems, 2010, Vol. 29, pp. 130-141.

[5] Young Mo Moon, Kota, "Design of reconfigurable machine tools", Journal of Manufacturing Science and Engineering, 2002, Vol. 124/2, pp.480-483,

[6] K.K Goyal,P.K Jain, M.Jain "Optimal configuration selection for reconfigurable manufacturing system using NSGA II and TOPOSIS", International Journal of Production Research,vol.50, 2011, pp.41754191 .

[7] Abderrahmane Bensmaine, M.Dahayene, L.Benyoussef, "A nondominated sorting genetic algorithm based approach for optimal machines selection in reconfigurable manufacturing environment", Journal of Computer and Industrial Engineering, 2013, Vol.66, pp. 519-524.

[8] P.Mohapatra, L.Benyoucef, M.k Tiwari, "Integration of process planning and scheduling through adaptive setup planning: a multiobjective approach", International Journal of Production Research, 2013, Vol.51, 7190-7208.

[9] Ahmed Azab, Bahman Naderi, "Modelling the problem of production scheduling for reconfigurable manufacturing systems", CIRP Conference on Intelligent Computation in Manufacturing Engineering, 2015, Vol.33, pp.76-80.

[10] N.Srinivas, Kalyanmoy Deb, "Multi -objective optimization using non-dominated sorting genetic algorithms", Journal of Evolutionary Computation, 1994, Vol.2/3, pp. 221-248. 
Proc. of Sixth International Conference On Advances in Civil, Structural and Mechanical Engineering -ACSM 2017 Copyright (C) Institute of Research Engineers and Doctors, USA .All rights reserved.

ISBN: 978-1-63248-118-4 doi: 10.15224/ 978-1-63248-118-4-75

[11] Hisao Ishibushi, Noritaka Tsukamoto, Yusuke Nojima, "Evolutionary many objective optimization: A short review", Evolutionary Computation IEEE, ISBN: 978-1-4244-1823-7, 2008, pp.2419-2426.

[12] A.Konak, D.W.Coit, A.E.Smith, "Multi-objective optimization using genetic algorithms", Reliability Engineering and System Safety, 2006, Vol.91/9, pp.992-1007.

About Author (s):

"Eram Asghar is research associate and holds her post graduate degree in Mechanical Engineering with specialization in manufacturing system design. Her research interests are optimal design and reconfiguration of manufacturing systems. She has also gained industrial experience in quality planning and assembly line break downs. "

\section{Annex.}

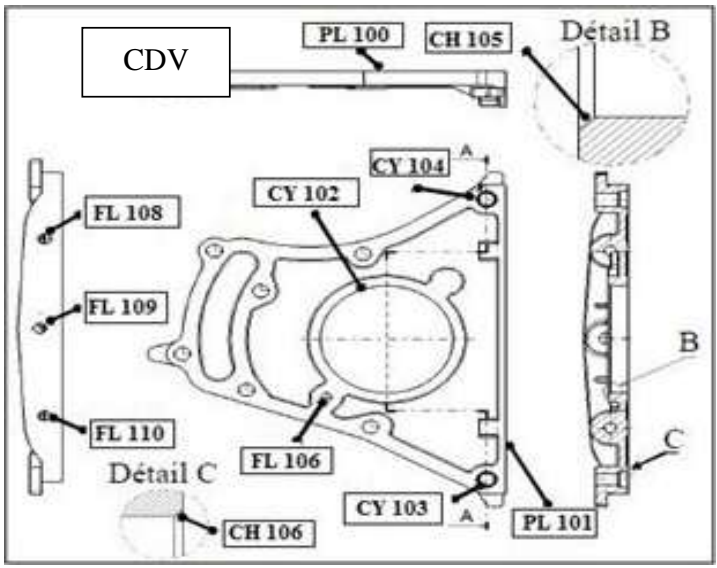

\begin{tabular}{|l|l|c|l|}
\hline \multicolumn{5}{|c|}{ Operation Data for Part CDV } \\
\hline Features & Operations & Op ID & TAD \\
\hline PL 100 & Rough Milling & 1 & $+\mathrm{x},+\mathrm{y},-\mathrm{z}$ \\
\hline PL 100 & Finish Milling & 2 & $+\mathrm{x},+\mathrm{y},-\mathrm{z}$ \\
\hline PL 101 & Rough Milling & 3 & $+\mathrm{z},+\mathrm{y}$ \\
\hline PL101 & Finish Milling & 4 & $+\mathrm{z},+\mathrm{y}$ \\
\hline CY 102 & Drilling & 5 & $+\mathrm{z},-\mathrm{z}$ \\
\hline CY 102 & Reaming & 6 & $+\mathrm{z},-\mathrm{z}$ \\
\hline CY 103 & Drilling & 7 & $+\mathrm{z},-\mathrm{z}$ \\
\hline CY 103 & Reaming & 8 & $+\mathrm{z},-\mathrm{z}$ \\
\hline CY 104 & Drilling & 9 & $+\mathrm{z},-\mathrm{z}$ \\
\hline CY 104 & Reaming & 10 & $+\mathrm{z},-\mathrm{z}$ \\
\hline FL 106 & Drill & 11 & $-\mathrm{z}$ \\
\hline FL 108 & Drill & 12 & $-\mathrm{z}$ \\
\hline FL 109 & Drill & 13 & $-\mathrm{z}$ \\
\hline FL 110 & Drill & 14 & $-\mathrm{z}$ \\
\hline
\end{tabular}

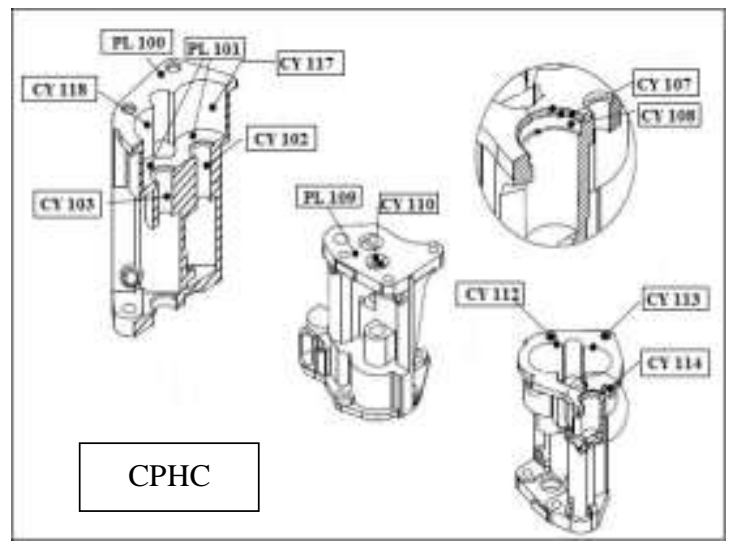

\begin{tabular}{|c|c|c|c|}
\hline \multicolumn{4}{|c|}{ Operation Data for Part CPHC } \\
\hline Features & Operations & OP ID & TAD \\
\hline Pl 100 & Rough Milling & 1 & $+x,+y,-z$ \\
\hline Pl 100 & Finish Milling & 2 & $+x,+y,-z$ \\
\hline Pl 101 & Rough Milling & 3 & $-z$ \\
\hline P1 101 & Finish Milling & 4 & $-z$ \\
\hline Pl 109 & Rough Milling & 5 & $+x,+y$ \\
\hline Pl 109 & Finish Milling & 6 & $+x,+y$ \\
\hline Cy 107 & Drilling & 7 & $-\mathrm{z}$ \\
\hline Cy107 & Boring & 8 & $-z$ \\
\hline Cy 107 & Reaming & 9 & $-z$ \\
\hline Cy 108 & Drilling & 10 & $-z$ \\
\hline Cy 108 & Boring & 11 & $-z$ \\
\hline Cy 108 & Reaming & 12 & $-z$ \\
\hline Cy 110 & Drilling & 13 & $-z$ \\
\hline Cy 110 & Boring & 14 & $-z$ \\
\hline Cy 110 & Reaming & 15 & $-z$ \\
\hline Cy 117 & Drilling & 16 & $-z$ \\
\hline Cy 117 & Boring & 17 & $-z$ \\
\hline Cy 118 & Drilling & 18 & $-z$ \\
\hline Cy 118 & Reaming & 19 & $-z$ \\
\hline Cy 102 & Drilling & 20 & $-z$ \\
\hline Cy 102 & Boring & 21 & $-z$ \\
\hline Cy 102 & Reaming & 22 & $-z$ \\
\hline Cy 103 & Drilling & 23 & $-z$ \\
\hline Cy 103 & Reaming & 24 & $-z$ \\
\hline $\mathrm{Cy} 112$ & Drilling & 25 & $-z$ \\
\hline Cy 113 & Drilling & 26 & $-z$ \\
\hline Cy 114 & Drilling & 27 & $-z$ \\
\hline Cy 115 & Drilling & 28 & $-z$ \\
\hline
\end{tabular}

